\title{
PlastShow 2002 - Iniciativa Bem Sucedida de Feira e Congresso num Único Evento
}

Realizada de 3 a 5 de junho, no Expo Center Norte, em São Paulo, a $1^{a}$ edição do PlastShow foi uma iniciativa bem sucedida de reunir a cadeia produtiva de plásticos. Organizado pela Aranda Eventos, coligada à Aranda Editora, editora da revista "Plástico Industrial", o evento atingiu números expressivos: - reuniu 108 expositores em 95 estandes distribuídos numa área de pouco mais de $2.200 \mathrm{~m}^{2}$; - contou com 468 congressistas assistindo às apresentações técnicas de 77 palestrantes; - recebeu 4.000 visitantes nacionais e internacionais.

Concebida para atender às necessidades técnicas e gerenciais dos transformadores de plásticos e de toda a cadeia produtiva envolvida com essa indústria, a feiracongresso apresentou os mais recentes desenvolvimentos tecnológicos que auxiliam transformadores e projetistas de peças e moldes a efetivamente resolver problemas do dia-a-dia, além de ter facilitado a integração dos profissionais da área com a troca e a disseminação de informações. O PlastShow 2002 teve seu escopo técnico fortalecido ao abrir espaço para temas que mobilizam e congregam todos os agentes do setorusuários do processo, revendedores e fabricantes de máquinas, empresas de engenharia, acessórios, periféricos, consultores, etc.

Realizadas diariamente em 3 sessões paralelas, as apresentações técnicas do congresso contaram com conceituados especialistas da indústria e de diversas instituições de pesquisa para a discussão dos seguintes temas:

$\sqrt{ }$ Processos de injeção, extrusão e automação industrial: avanços das pesquisas em processamento por injeção e por extrusão, estudo de casos, novos equipamentos, periféricos e inovações tecnológicas na fabricação e montagem de componentes, produtividade e competitividade;

$\sqrt{ }$ Construção de moldes e matrizes: diagnóstico da indústria de ferramentaria, com apresentação de casos práticos de excelência na qualidade dos projetos, conservação e manutenção de ferramentas, aplicação de técnicas e softwares de simulação e parametrização; resultado das recentes pesquisas sobre novos materiais; sensores e componentes para moldes e matrizes;

$\sqrt{ }$ Técnicas e Análises de laboratório e em linha de produção (in-line): o controle de qualidade de produtos finais, a caracterização de propriedades dos polímeros, a instrumentação e o monitoramento dos processos de fabricação de produtos semi-acabados e acabados.

$\sqrt{ }$ Processos de Transformação Alternativos: a evolução tecnológica ocorrida em processos como rotomoldagem, pultrusão, expansão, além de processos de soldagem e montagem

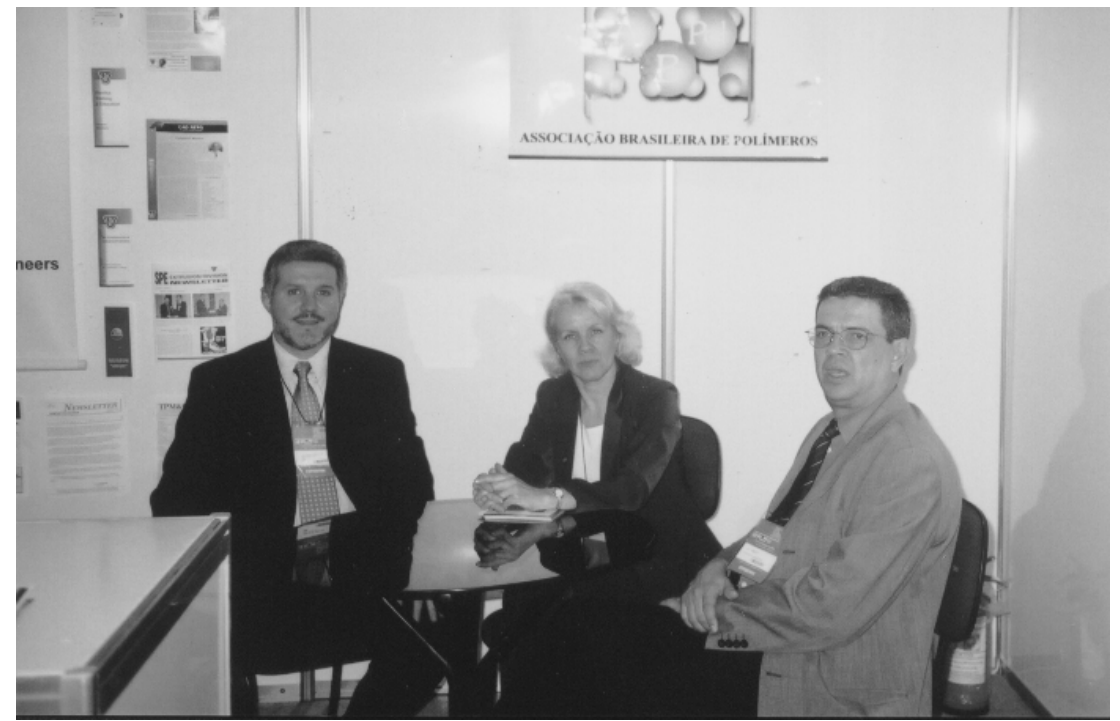

Estande da ABPol com a presença de Domingos Jafelice (Presidente), Fátima Cordebello (Secretária Executiva) e José Roberto Gonçalves, Diretor da Aranda. 


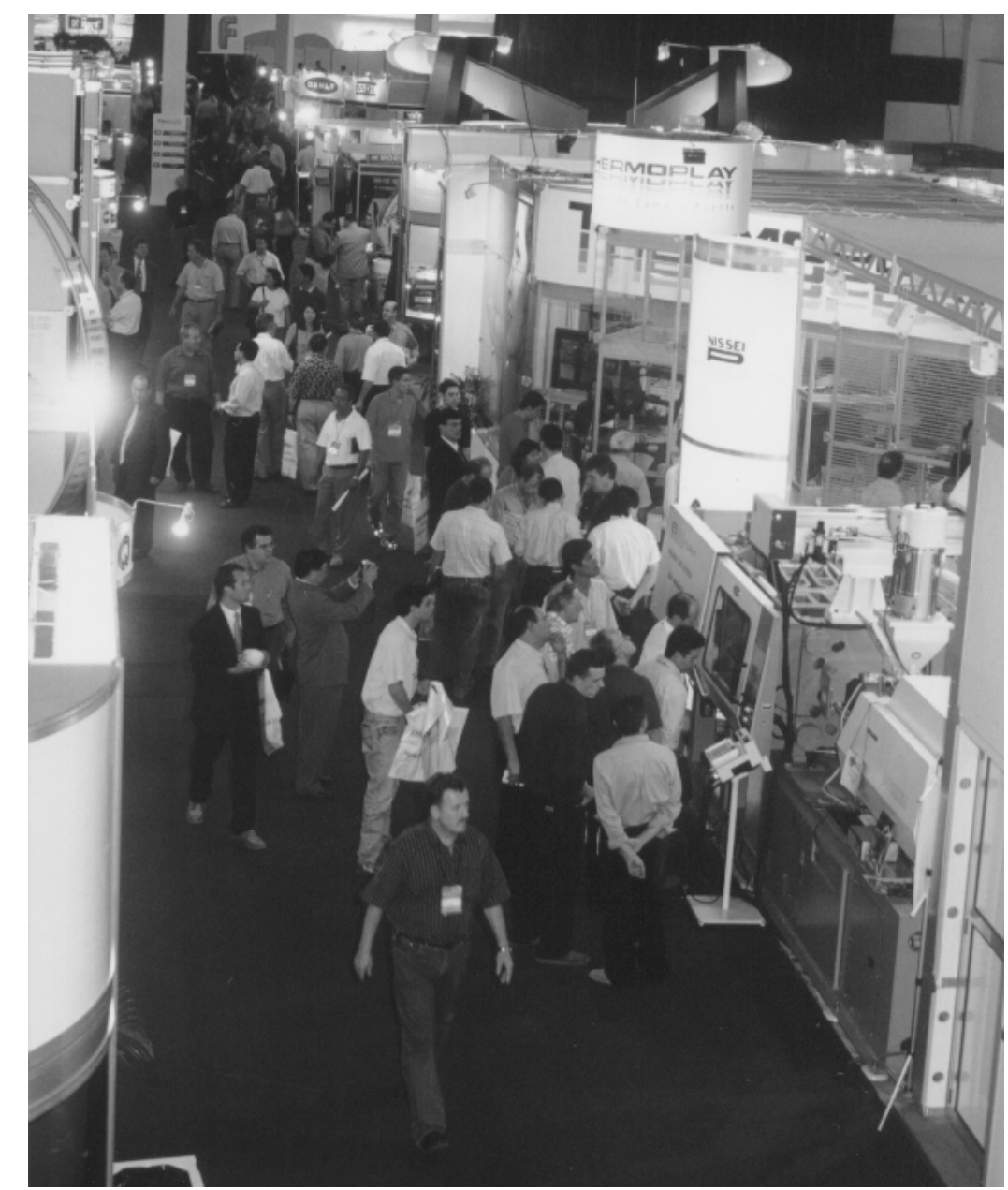

Participação marcante de visitantes aos estandes.

de componentes em materiais poliméricos.

$\sqrt{ }$ Processo de Sopro, Termoformagem e Automação Industrial: os avanços das pesquisas em processamento por sopro e termoformagem, e as inovações tecnológicas na fabricação de produtos, visando a otimização dos processos produtivos; novas aplicações de CAD e CAE para análises do processo de conformação; a produtividade alcançada com as novas tecnologias nas linhas de produção.

$\sqrt{ }$ Gestão de Projetos e Desenvolvimento de Produtos: trabalhos realizados por empresas e universidades em gerenciamento de projetos, com o objetivo de melhor controlar, agilizar e reduzir custos no processo de desenvolvimento de novos produtos; a gestão do conhecimento; a criação do modelo de referência; capacitação de profissionais envolvidos com aspectos técnicos e/ou gerências do setor.

$\sqrt{ }$ Materiais: Termoplásticos de uso geral e Aditivos: trabalhos nas áreas científica, tecnológica e mercadológica de resinas termoplásticas de uso geral, aditivos modificadores de propriedades, expandidos e laminados; aspectos decorativos e funcionais correlacionados aos produtos finais elaborados.

$\sqrt{ }$ Elastômeros Termoplásticos: trabalhos nas áreas científica, tecnológica e mercadológica de materiais termoplásticos elastoméricos; o desenvolvimento de novas aplicações; análise do rápido crescimento do mercado e suas vantagens competitivas.

$\sqrt{ }$ Design, Prototipagem e Ferramental Rápido: aspectos de design; as soluções em sistemas computacionais de simulação 3D; análise estrutural e as possibilidades de integração tecnológica no desenvolvimento e produção de componentes plásticos; a construção de protótipos em diversas tecnologias; a produção de pequenas séries para homologação de produtos, ou em caráter de produção de pequena escala.

$\sqrt{ }$ Reciclagem e Plásticos Biodegradáveis: resultado dos últimos desenvolvimentos realizados pela indústria e pela área acadêmica em redução, recuperação e reciclagem de polímeros pós-consumo e resíduos industriais; meio-ambiente e as características de biodegradabilidade dos novos polímeros e suas aplicações nos segmentos de embalagens (filmes e frascos) para as indústrias de produtos descartáveis, cosméticos, alimentícia e agrícola.

$\sqrt{ }$ Materiais: Termoplásticos de Engenharia, Especiais e Compostos: trabalhos nas áreas científica, tecnológica e mercadológica destes termoplásticos de alta performance e as aplicações em projetos de engenharia; trabalhos sobre 


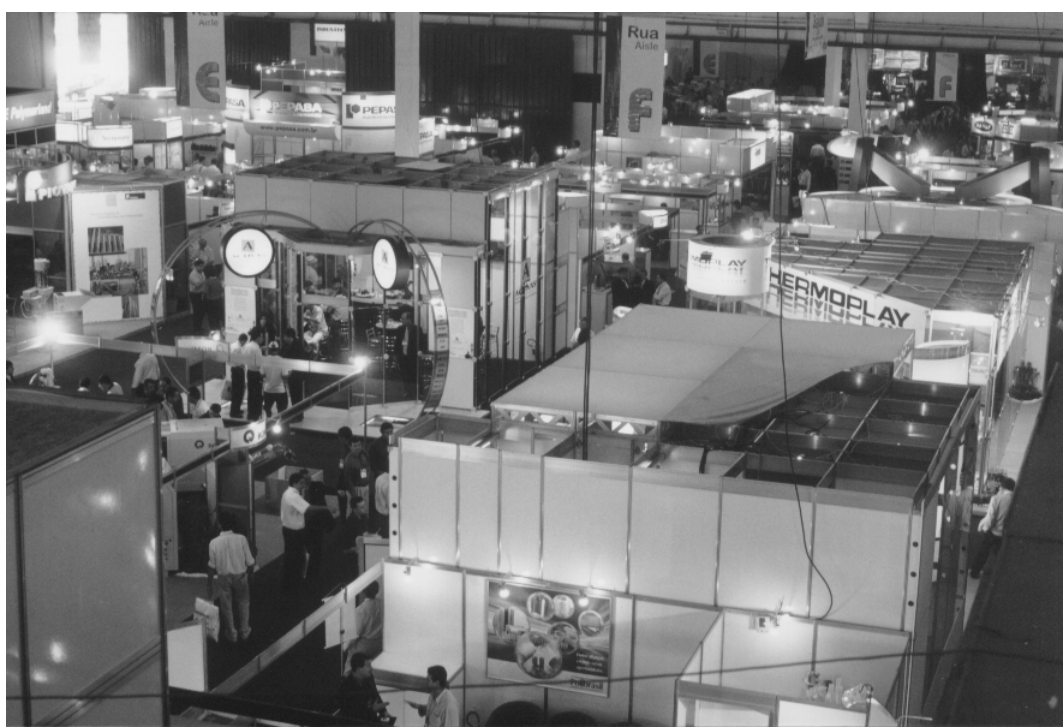

Vista de alguns estandes apresentados na feira

compostos, nanocompósitos, blendas e suas relações processamento-estrutura-propriedades; potencialidades de desenvolvimento de novas aplicações de polímeros especiais na indústria eletro-eletrônica e as oportunidades de substituição de materiais tradicionais por novos materiais.
O evento demonstrou que atendeu as expectativas dos congressistas, expositores e visitantes da feira, promovendo a indústria, apresentando os mais recentes resultados das pesquisas realizadas no país e gerando uma excelente oportunidade para um maior contato entre a indústria de transformação de termoplásticos e o meio acadêmi- co brasileiro, que cada vez mais está contribuindo para o desenvolvimento tecnológico do Brasil. Diversas instituições de pesquisa na área de polímeros, presentes em estandes gentilmente cedidos pela organização, emprestaram seu apoio e colaboração para que o PlastShow 2002 atingisse plenamente seus objetivos iniciais. A ABPol agradece a oportunidade que teve de participar do evento. Finalizando esta rápida retrospectiva, deve-se considerar que a temática desenvolvida e a análise do perfil dos visitantes levantado pelos organizadores por si se constituem em indicadores do nível de atendimento das expectativas dos participantes do PlastShow: - 75\% eram transformadores de plástico; - 20\% eram usuários e 5\% recicladores; $64,6 \%$ eram diretores ou gerentes, $13,7 \%$ eram proprietários ou presidentes de empresa; $11,7 \%$ eram engenheiros e $10 \%$, técnicos. Mais uma vez, os parabéns à Aranda Eventos. 